\title{
LEITURA E DISCURSO: UMA ANÁLISE DAS ATIVIDADES DE LEITURA E COMPREENSÃO EM COLEÇÃO DIDÁTICA DO ENSINO MÉDIO
}

\author{
Luciano Taveira de AZEVEDO \\ Escola Técnica Estadual Cícero Dias \\ lucianoazevedo7@gmail.com
}

\begin{abstract}
Resumo: Neste artigo, buscamos respaldo teórico nas reflexões propostas por Bakhtin (2002; 2006); Bakhtin/Voloshinov (1976; 2002); Maingueneau (1995; 2005; 2006; 2008) e Orlandi (2001a; 2001b) para pensar o funcionamento discursivo do texto e suas implicações no processo de leitura. O presente trabalho tem como objetivo analisar as atividades de leitura propostas no livro didático Português: linguagens de Cereja e Magalhães (2005), a fim de entender como os autores trabalham aspectos da discursividade em seção dedicada à compreensão textual. Dentre os métodos nos quais a pesquisa qualitativa se desdobra, optamos pela Análise de Conteúdo por entendermos que esse método permite o estudo de textos impressos.
\end{abstract}

Palavras-chave: Leitura. Compreensão. Livro didático. Funcionamento discursivo.

Abstract: In this article, we seek theoretical support grounded on the reflections proposed by Bakhtin (2002, 2006), Bakhtin/Voloshinov (1976; 2002), Maingueneau (1995; 2005; 2006; 2008) and Orlandi (2001a; 2001b), to consider the discursive functioning of the text and its implications for the reading process. This work aims to analyze the reading activities proposed on the textbook Português: Linguagens by Cereja and Magalhães (2005) in order to understand how the authors work on discursive aspects in a section devoted to textual comprehension. Among the methods in which qualitative research is grounded, we have chosen Content Analysis because we feel that this method allows the study of printed texts.

Keywords: Reading. Comprehension. Textbook. Discursive operation.

Embora muito se tenha escrito e dito sobre questões concernentes à leitura, sobretudo à leitura realizada no ambiente escolar, as pesquisas acadêmicas mais recentes desenvolvidas no campo da Linguística Aplicada demonstram que as questões que envolvem a leitura em suas diversas práticas e modalidades ainda continuam sendo o tema na ordem do dia. O número expressivo de publicações acadêmicas que têm como objeto a leitura em suas diferentes práticas aponta para o fato de que a questão da leitura se apresenta 
como um objeto complexo (SIGNORINI, 2004) e multifacetado. Dito dessa forma, temos que a leitura, por ser constitutivamente heterogênea, mobiliza diferentes olhares teóricos que procuram dar conta das diversas facetas que constituem o plano da sua realização.

As atividades de leitura em livros didáticos de Português do Ensino Médio (daqui em diante, EM) são retomadas neste artigo que desloca o estatuto do texto e, por conseguinte, da leitura, de uma perspectiva estritamente textual para uma visão do texto como discurso. Esse entendimento do funcionamento discursivo do texto impõe outra forma de pensar leitura e compreensão, uma vez que partimos de uma perspectiva teórica que envereda pela via da Análise do Discurso de linha francesa a partir das contribuições de Bakhtin (2006), Bakhtin/Voloshinov (2002) Maingueneau (2005; 2008a; 2008b) e Orlandi (1988; 1996; 1999; 2001a; 2001b). Leitura e compreensão, nessa perspectiva, implicam um trabalho sobre os sentidos e não apenas um trabalho de identificação de um ou mais sentidos atribuíveis a um texto.

Apoiados nesse aparato teórico e mediados pelas questões de pesquisa descritas a seguir, desenvolvemos uma reflexão analítico-crítica das atividades de leitura propostas na obra seriada Português: linguagens dos autores William Roberto Cereja e Thereza C. Magalhães: a) As atividades de leitura propostas no livro didático de português (doravante, LDP) encontram-se em consonância com aquilo que o(s) autor(es) afirma(m) no Manual do Professor e com a teoria adotada? b) Em se tratando de um LDP cujas bases teóricas encontram-se filiadas à Análise do Discurso, como as atividades de leitura e compreensão estão organizadas a fim de permitir a leitura da discursividade? Balizados por essas questões, estabelecemos o objeto da nossa pesquisa, articulamos aparatos teóricos e definimos o caminho metodológico.

\section{Do texto ao discurso}

O primeiro aspecto a considerar na construção de uma concepção de texto é seu caráter global, ou seja, um texto é concebido como "um todo, como 
constituindo uma totalidade coerente" (MAINGUENEAU, 2005, p. 57). Em seus aspectos estruturais, organizadores do corpo textual, apresenta coerência, coesão, não-contradição, progressão etc. $\mathrm{Na}$ perspectiva dos primeiros trabalhos elaborados no campo da Linguística Textual, esses aspectos, dentre outros, asseguram a textualidade de um texto. Embora concordemos que um texto se caracteriza por seus aspectos estruturais e linguísticos, acreditamos que não se define apenas por eles mesmos nem como objeto fechado. Conceber o texto como um artefato construído a partir da realização de regras de boa formação textual é reduzi-lo ao nível linguístico sem remetê-lo às condições de produção. Desse modo, não conceituamos o texto a partir dos seus aspectos estritamente linguísticos, mas procuramos "re-definir a noção de texto a partir da materialidade do discurso, isto é, da materialidade linguísticohistórica" (ORLANDI, 2001b, p. 74). Assim, os processos de textualização, vistos por um viés discursivo, não se reduzem aos aspectos meramente formais, mas são definidos em relação ao discurso, ou seja, aos interlocutores em interação discursiva, à situação pragmática e ao contexto sócio-histórico.

Pensar o texto e seu funcionamento em relação ao discurso é remetê-lo aos processos históricos de produção de sentidos que se inscrevem no corpo textual. Assim sendo, pensamos o texto como processo que envolve os sujeitos, a história e os lugares sociais de onde emerge. Em suma, buscamos entender o texto funcionando discursivamente e sua historicidade.

1.2 Constituição, formulação e circulação dos discursos

Os sentidos produzidos por um discurso compreendem três momentos intrinsecamente ligados: constituição, formulação e circulação (ORLANDI, 2001b). A articulação desses três momentos, indissoluvelmente constituídos, tece o corpo dos sentidos; corpo inscrito na história e produto de um processo que percorre as práticas sociais nas quais os sentidos se ancoram. Em Bakhtin (1976, p. 11), lemos que

a vida, portanto, não afeta um enunciado de fora; ela penetra e exerce influência num enunciado de dentro, enquanto unidade e comunhão da existência que 
circunda os falantes e unidade e comunhão de julgamentos de valor essencialmente sociais, nascendo deste todo sem o qual nenhum enunciado inteligível é possível.

Nesse quadro mais amplo que engloba as determinações históricosociais, Orlandi (2001b) situa a instância da constituição do discurso. Os processos de inscrição histórica dos sentidos, ou seja, a historicidade dos textos e dos sentidos, implicam as relações que todo discurso estabelece com outros discursos a partir das relações dialógicas. Entendemos com Maingueneau (2005) que todo discurso produz sentido no interior de outros discursos, lugar no qual ele deve traçar seu caminho.

$\mathrm{Na}$ formulação, temos o sujeito articulando a materialidade da história à materialidade do discurso em circunstâncias específicas de enunciação. Nesse sentido, todo processo de formular, ou seja, de dar corpo aos sentidos, é um acontecimento que envolve os sujeitos situados numa dada circunstância social (BAKHTIN/VOLOSHINOV, 2002). A produção de um discurso inscreve-se em um lugar (social, institucional, ideológico) de enunciação. Ao enunciar, o sujeito filia seu discurso a um determinado lugar que, por sua vez, legitima e autoriza esse discurso. Assim, os sujeitos não apenas produzem discursos a partir de lugares sócio-institucionais bem precisos, como inscrevem suas palavras em instâncias de enunciação que determinam os sentidos possíveis de um texto. É nessa direção que Bakhtin/Voloshinov (2002, p. 106) afirmam que "o sentido da palavra é totalmente determinado por seu contexto." Se pensarmos que o lugar (a instituição, a posição social, etc.) de onde o sujeito enuncia é constitutivo do contexto que determina a produção de sentidos, podemos concluir com os autores que o lugar de enunciação não é indiferente à constituição e formulação dos discursos e que, por sua vez, recebem desse lugar a legitimação que os faz circular e produzir efeitos.

Os discursos não são apenas sua constituição e formulação, mas também os lugares e os meios materiais por onde circulam. A esse respeito, Maingueneau (2005, p. 71) faz as seguintes considerações:

Vimos que é necessário reservar um lugar importante ao modo de manifestação material dos discursos, ao seu suporte, bem como ao seu modo de difusão: 
enunciados orais, no papel, radiofônicos, na tela do computador etc. Essa dimensão da comunicação verbal foi durante muito tempo relegada a segundo plano. (...) Hoje, estamos cada vez mais conscientes de que o mídium não é um simples "meio" de transmissão do discurso, mas que ele imprime um certo aspecto a seus conteúdos e comanda os usos que dele podemos fazer.

Os lugares sociais e os meios ou suportes pelos/nos quais os discursos circulam não são meros acessórios indiferentes à produção de sentidos. Antes, esses suportes materiais constituem os processos de formulação e determinam, por assim dizer, seu conteúdo, composição, bem como impõem um modo de ler e interpretar determinados discursos.

\section{Análise}

A partir dos critérios metodológicos estabelecidos, elegemos a seção Leitura que reúne perguntas que se encaminham exclusivamente para uma atividade de interpretação/compreensão do texto. Nessa seção, os textos são predominantemente literários. Em algumas atividades, outros textos são convocados a fim de conduzir o aluno-leitor a refletir sobre aspectos dialógicos e intertextuais que constituem o processo de produção textual. Embora assim procedam os autores, o texto literário ocupa sempre um lugar central nos exercícios de compreensão.

Faz-se mister esclarecer que a análise das atividades de compreensão do livro didático Português: linguagens apresentada neste artigo não se configura em uma análise do discurso produzido no livro didático estudado, mas em entender como os autores têm trabalhado aspectos da discursividade nas atividades de leitura. Partindo da perspectiva teórica adotada, elaboramos o seguinte quadro tipológico:

Quadro 1 - Tipologia de Perguntas de Compreensão Textual

CONSTITUIÇÃO

Perguntas que trabalham o contexto sócio-histórico mediato e relações dialógicas:

Esse tipo de pergunta encaminha a reflexão do aluno-leitor para aspectos que envolvem o contexto sócio-histórico amplo e as relações que todo discurso estabelece com outro discurso para polemizar, excluir, legitimar(-se) etc. São perguntas que 
trazem para a reflexão do aluno aspectos mais abrangentes que constituem os discursos e determinam seu modo de produção.

FORMULAÇÃO

Perguntas que trabalham o contexto imediato e os enunciadores:

Perguntas que pertencem a esta categoria conduzem o olhar do aluno-leitor para os aspectos pragmáticos da produção discursiva, ou seja, o contexto imediato e os enunciadores.

\section{CIRCULAÇÃO}

Perguntas que trabalham os lugares e os meios sociais por onde o discurso circula:

Essas perguntas dizem respeito aos lugares sociais por onde o discurso circula e os meios (jornal, TV, banner, panfleto etc.) que veiculam determinado discurso.

Partindo desse quadro tipológico, entendemos que as perguntas podem trazer para a reflexão do aluno-leitor fatores da discursividade que se encaminham pelo nível da constituição, da formulação ou da circulação do discurso.

\subsection{Constituição}

A Unidade 1 do livro do $1^{\circ}$ ano traz como título Linguagem e Literatura e apresenta sete capítulos, cujos temas atravessam saberes variados que passam pela linguagem, comunicação, introdução à Literatura, introdução aos gêneros do discurso, gramática e produção textual. Essa atividade (figura 1) encontra-se no capítulo $O$ que é literatura? e tem, por finalidade precípua, ensinar estilos de época, estilo pessoal e tradição literária.

Fig. 1 


\section{Leitura}

A seguir, você vai ler e comparar versos de dois poemas: o texto I é de Castro Alves, poeta romântico que viveu no século XIX. O texto II é de Manuel Bandeira, poeta modernista que viveu no século XX.

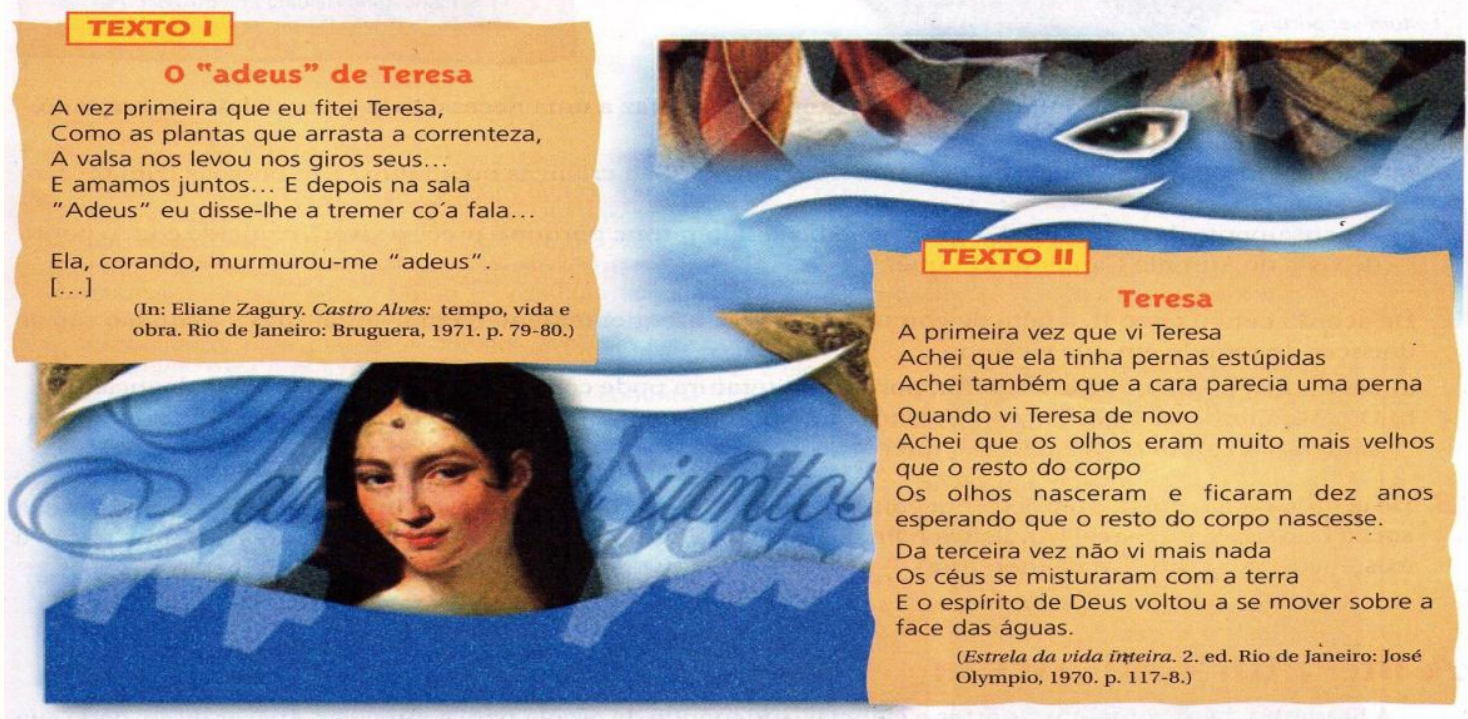

1. Manuel Bandeira, por meio do poema “Teresa”, estabelece um diálogo com o poema "O 'adeus' de Teresa”, contrapondo sua visão da mulher amada à do poeta Castro Alves.

a) Em qual dos dois textos a mulher é encarada como um ser superior? No texto I

b) E em qual dos textos a mulher é tratada como um ser de aparência feia e ao mesmo tempo sedutora? No texto II.

3. Compare a linguagem dos dois textos. Em qual deles, a linguagem:

a) É mais elevada, sustentando a idealização da mulher e do amor? No texto 1 .

b) É irônica e cotidiana, buscando um modo de dizer próximo da fala? No texto 11 .

(Português: linguagens, 2005)

- A atividade proposta apresenta dois textos que pertencem a épocas e movimentos literários diferentes. O texto I foi escrito pelo poeta romântico Antônio de Castro Alves e pertence à $3^{\underline{a}}$ geração do movimento literário, denominado Romantismo, que data do século XIX. Sobre a transposição desse poema para o livro didático, atentamos para o fato de que o texto não é reproduzido na íntegra, de modo que o aluno-leitor não terá acesso ao todo do enunciado. O texto II, escrito por Manuel Bandeira, pertence à primeira fase modernista que teve seu início com a Semana de Arte Moderna em 1922.

Essa breve contextualização histórica dos textos da atividade proposta no LDP justifica-se pelo fato de que, numa perspectiva discursiva, a leitura de um texto "deve se ater a mostrar a articulação entre o intradiscursivo e o extradiscursivo, a imbricação entre uma representação do mundo e uma atividade enunciativa" (MAINGUENEAU, 2008a. p. 40). 
Nesse primeiro recorte que operamos, temos uma atividade que atende a dois expedientes: caracterizar e distinguir estilos de época, estilo pessoal e tradição literária e trabalhar a interpretação em consonância com a proposta dos autores constante do Manual do Professor, onde afirmam que "embora a história da literatura seja uma referência e um fio condutor para o desenvolvimento dos conteúdos, a leitura e a interpretação do texto literário ganham o primeiro plano da abordagem" (Cereja;Magalhães, 2005, p. 3).

A atividade proposta compreende três grupos de perguntas sobre as poesias de Castro Alves e Manuel Bandeira que estão organizadas em torno da relação dialógica que os textos entretêm entre si. Desse modo, as perguntas se encaminham na direção de um trabalho sobre a natureza dialógica dos textos, uma vez que orientam o olhar do aluno-leitor para a relação que um discurso estabelece com outro no momento da sua constituição.

A questão 1,

Manuel Bandeira, por meio do poema "Teresa", estabelece um diálogo com o poema "O 'adeus' de Teresa” contrapondo sua visão da mulher à do poeta Castro Alves.

a) Em qual dos dois textos a mulher é encarada como um ser superior?

b) E em qual dos textos a mulher é tratada como um ser de aparência feia e ao mesmo tempo sedutora?,

embora traga no enunciado introdutório informações que apontam para o caráter dialógico dos textos, apenas refere esse aspecto sem aprofundá-lo nas perguntas seguintes. Assim, a relação dialógica estabelecida entre os discursos e mencionada pelos autores, funciona, na questão, apenas como um pano de fundo desvinculado do funcionamento do discurso que foi construído a partir de outro e com o qual dialoga. Nas perguntas a) e b) que seguem ao enunciado-base da questão, os autores apagam a relação dialógica e propõem questões que visam à identificação do texto que apresenta um determinado conteúdo. Assim, a relação dialógica que o LDP faz emergir aos olhos do aluno-leitor permanece como um dado meramente informativo e periférico, desvinculado do funcionamento discursivo dos textos que buscam se legitimar 
ao estabelecer essas relações.

Na questão 2,

No texto I, o amor é resultado de uma paixão instantânea e incontrolável equivalente ao amor à primeira vista. Como se dá a descoberta do amor no texto II?,

a pergunta Como se dá a descoberta do amor no texto II? aponta para um conteúdo objetivamente inscrito no texto. Embora a resposta apresente um nível de complexidade maior que as perguntas $a$ e $b$ da questão 1 , essa complexidade não é construída pela pergunta, posto que não desafia o alunoleitor a refletir sobre o tema do poema Teresa a partir da relação dialógica estabelecida entre os textos. A complexidade é dada pelo próprio texto que exige do aluno-leitor a capacidade de inferir sentidos possíveis para as imagens criadas pelo poeta. Uma vez que, na própria questão, os autores caracterizam o amor vivenciado pelo poeta no Texto I, o aluno não se preocupa em voltar a esse texto que já foi supostamente interpretado a fim de estabelecer relações entre os textos para responder a atividade, de modo que sua atenção recai apenas sobre o segundo texto.

Essas constatações evidenciam o hiato existente entre teoria e prática na formulação de LDPs. Além da operacionalização precária no trabalho com aspectos da constituição dos discursos, nesse caso, o dialogismo, verificamos também a falta de outros fatores que entram em jogo nesse processo de produção dos discursos e dos sentidos e que poderiam ser mobilizados para tratar tanto a compreensão quanto o estilo pessoal e de época. Entre esses fatores, podemos citar os enunciadores, as condições mediatas e imediatas e o suporte material de circulação desses discursos. Partindo desse pressuposto, estilo pessoal e estilo de época poderiam ser trabalhados, também, em relação aos processos discursivos que os determinam e não apenas a características inerentes ao texto que precisam ser identificadas a fim de enquadrar o texto literário neste ou naquele estilo. A obra literária possui uma data e um lugar de produção e está inserida num processo sócio-histórico mais amplo, de modo que as relações dialógicas estabelecidas ao longo do processo de criação, os 
sujeitos envolvidos, a escolha do gênero e o suporte de publicação e divulgação de determinada obra encontram-se indissoluvelmente ligados ao estilo pessoal ou de época. Em Maingueneau (1995, p. 66-67), temos que "não se tem, por um lado, um texto e, por outro, o lugar e o momento de sua enunciação, mas o 'modo de emprego' é uma dimensão completa do discurso."

\subsection{Formulação}

A atividade abaixo (figura 2) constitui um grupo de perguntas que tem por finalidade introduzir o aluno do $1^{\circ}$ ano do Ensino Médio no universo literário a partir da diferenciação entre linguagem literária e não-literária, temas da literatura e objetivos da produção estética. Essa atividade pode ser encontrada na Unidade 1, cujo título é Linguagem e literatura. Com o objetivo de trabalhar o viés social da literatura, os autores incluíram a atividade no capítulo 3 denominado $O$ que é literatura?

O poema estudado no sub-título Literatura: o encontro do individual com o social é do poeta africano José Craveirinha, cujas informações sobre sua participação em processos políticos e produção literária são dadas no boxe que acompanha a atividade.

$\mathrm{Na}$ íntegra, a atividade compreende 6 questões. Uma vez que apenas a primeira e a segunda questão nos interessam diretamente por apresentarem elementos que apontam para aspectos da formulação dos discursos, decidimos recortá-las com a finalidade de focalizar apenas aspectos concernentes ao aspecto em questão.

Fig. 2 
Leitura

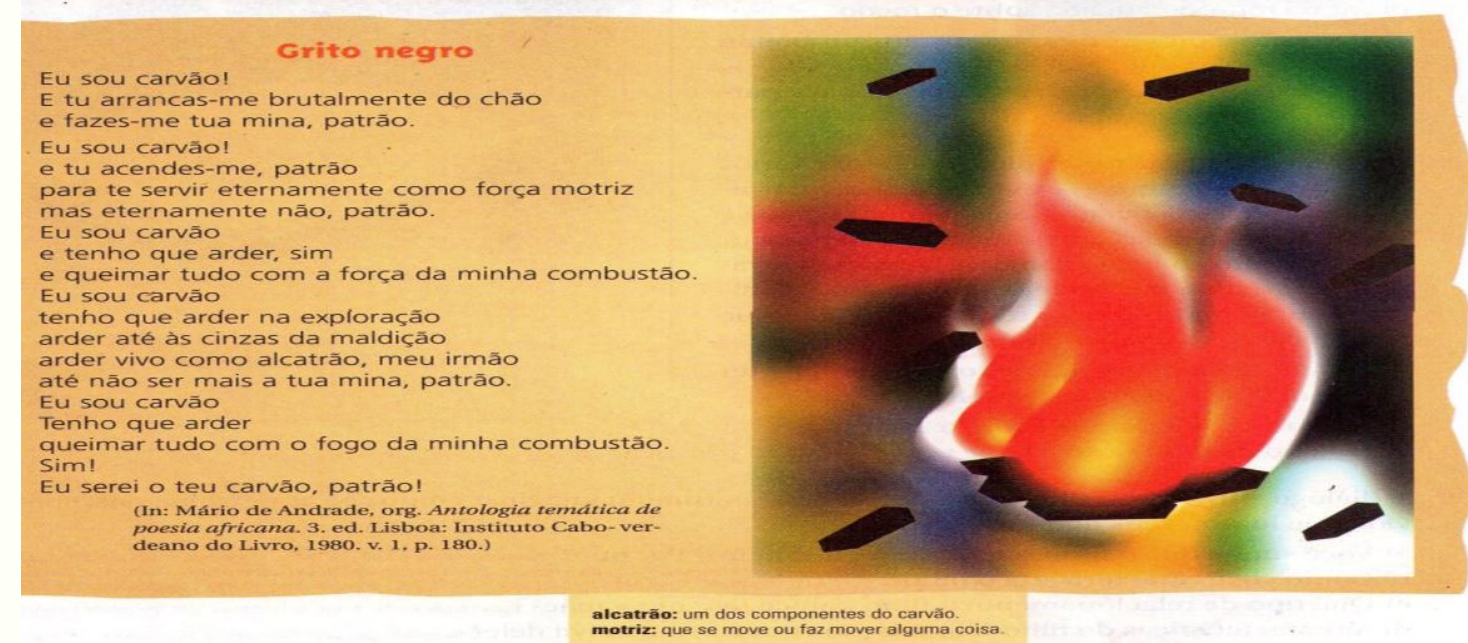
alcatrāo: um dos componentes do carvão.
motriz: que se move ou faz mover alguma coisa

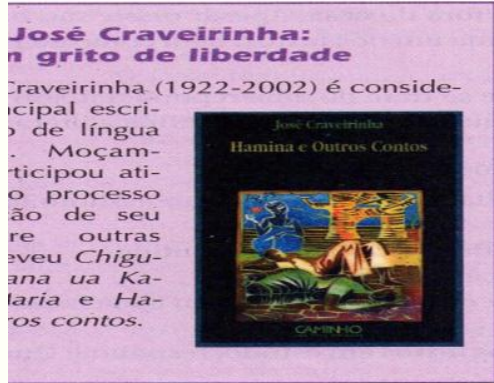

1. O texto lido é um poema, um dos vários gêneros literários. Como ocorre na maior parte dos poemas, há nele uma voz que fala, a que chamamos eu lírico ou eu poético. Nos poemas, o elemento em destaque é geralmiente o próprio eu lírico, que ali expressa seus pensamentos e sentimentos. No poema lido, o eu lírico é um negro que fala de si mesmo e de sua relação com o outro, no caso, o patrão. Que tipo de relacionamento existe entre o eu lírico e o patrão?

2. Os poemas geralmente utilizam uma linguagem plurissignificativa, isto é, uma linguagem figurada, em que as palavras apresentam mais de um sentido. 0 úrico do palavras apresentam thais de um sentido. poema lido, por exemplo, chama a si mesmo de carvăo.

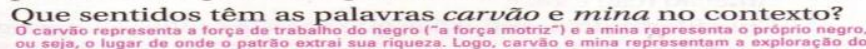

(Português: linguagens, 2005)

Nas questões 1 e 2, há um notório interesse dos autores em contextualizar o poema a partir de referências feitas aos interlocutores e ao contexto envolvidos no processo enunciativo. Desse modo, as perguntas contemplam aspectos discursivos fundamentais para a compreensão da discursividade: quem fala, para quem se fala e o contexto de produção do discurso. Nesse sentido, podemos constatar que o texto foi, de certo modo, historicizado para o aluno-leitor.

Não obstante esses elementos que configuram a historicidade do texto tenham sido trazidos para a consideração do aluno, ainda é possível identificar limites que se repetem no modo como aspectos ligados à formulação são trabalhados numa perspectiva que se propõe trabalhar com a leitura da discursividade. Aquilo que Orlandi (2001b: p.88) diz ser objetivo da análise de 
discursos pode ser deslocada para uma proposta de leitura dos mecanismos históricos de produção de sentidos:

Há diferentes processos de significação que acontecem no texto, processos que são função da historicidade, ou seja, da história do(s) sujeito(s) e do(s) sentido(s) do texto enquanto discurso. O objetivo da análise é então compreender como um texto funciona, como ele produz sentidos, sendo ele um objeto linguísticohistórico. É apreender sua historicidade.

Deslocando as considerações da autora acerca dos procedimentos analíticos seguidos por um(a) analista de discurso para uma proposta didáticopedagógica de ensino de leitura, podemos concluir que as perguntas 1 e 2 da Fig. 2 permanecem num nível bastante superficial no que diz respeito à compreensão do funcionamento discursivo do poema analisado. Podemos acrescentar que os interlocutores e o contexto são trazidos mais com a finalidade de levar o aluno-leitor a inferir sentidos para o texto e/ou palavras do que possibilitar uma leitura mais acurada acerca dos processos discursivos que definiram aspectos como a coesão do poema, por exemplo. Nesse sentido, a questão 1 ,

O texto lido é um poema, um dos vários gêneros literários. Como ocorre na maior parte dos poemas, há nele uma voz que fala, a que chamamos eu lírico ou eu poético. Nos poemas, o elemento em destaque é geralmente o próprio eu lírico que ali expressa seus pensamentos e sentimentos. No poema lido, o eu lírico é um negro que fala de si mesmo e de sua relação com o outro, no caso, o patrão. Que tipo de relacionamento existe entre o eu lírico e o patrão?

embora em seu enunciado faça referência aos interlocutores, direciona a resposta e aponta para um conteúdo objetivamente inscrito no texto sem problematizar a relação existente entre as contradições sociais e o modo de textualização.

Desse modo, não obstante o LDP assumir uma nova roupagem que vai da adoção de uma teoria à organização gráfica, ainda é possível identificar, não raras vezes, atividades que, como afirma Voese (2004, p. 128), desmerecem "a inteligência dos alunos ao negar-lhes as oportunidades e os 
meios para se construírem como sujeitos." Nesse tipo de atividade, visa-se a reprodução de sentidos dados pelo texto e/ou estabelecidos pelos autores nas sugestões de respostas que acompanham as perguntas.

O direcionamento dado pelo enunciado da questão e a resposta fixada no manual do professor - à qual o aluno-leitor se vê coagido a ajustar-se constroem os limites estreitos por onde esse leitor deve transitar sem possibilidade a uma voz que permita assumir posições ativas na interação que estabelece com as vozes que tecem o arranjo textual. Souza (1999, p. 27) considera que "independente do livro didático adotado ou da disciplina abordada, o que se constata é que o livro didático constitui um elo importante na corrente do discurso da competência: é o lugar do saber definido, pronto, acabado e dessa forma, fonte última (e às vezes, única) de referência." A crença nesse saber definido veiculado pelo LDP (re)produz modelos de ensino de leitura e, por conseguinte, atitudes leitoras que não vão além da orientação dada pelos autores nas diferentes atividades que envolvem os objetos de ensino selecionados.

Essa orientação para a identificação de conteúdos expressos no texto destitui o processo de leitura e de textualização do seu caráter eminentemente interativo, polissêmico, numa palavra: histórico. Reforçar a crença de que o texto é um objeto transparente e desvinculado das condições sócio-históricas de produção que o engendraram é perder de vista a concepção de texto como o lugar do jogo de sentidos, do trabalho da linguagem e funcionamento da discursividade (ORLANDI, 2001a).

\subsection{Circulação}

Essa atividade (figura 3) integra a Unidade 1 do livro do $1^{\circ}$ ano e tem como título Linguagem e Literatura. Ela apresenta sete capítulos, cujos temas atravessam saberes variados que passam pela linguagem, comunicação, introdução à Literatura, introdução aos gêneros do discurso, gramática e produção textual. As perguntas analisadas se encontram no capítulo $O$ que é literatura? e têm por finalidade precípua definir literatura a partir do confronto 


\section{com textos tidos como não literários e dos pareceres de especialistas e autores.}

Fig. 3

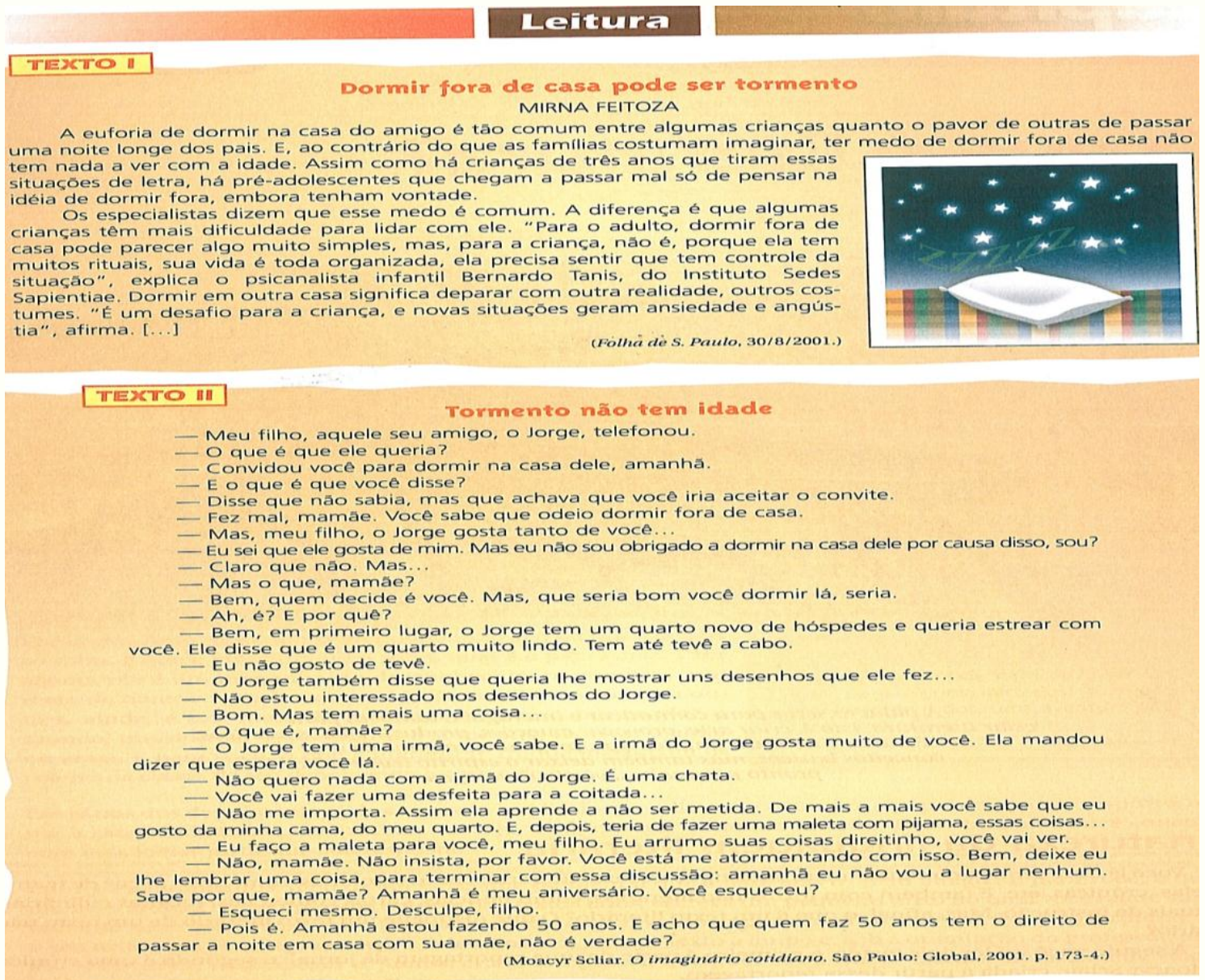

1. O texto I foi publicado num jornal e trata do medo de algumas pessoas de dormir fora de casa. De acordo com o texto: Năo, atinge crianças e tambén a) Esse medo se restringe às crianças? b) Por que dormir fora de casa causa tanto des-

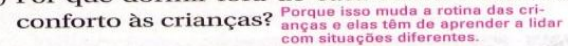

2. O texto II foi criado pelo escritor Moacyr Scliar a partir da reportagem lida sobre o medo.

a) Qual dos dois textos trata de um problema concreto da realidade? o texto 1 .

b) E qual deles cria uma história ficcional a partir de dados da realidade? o texto 11.

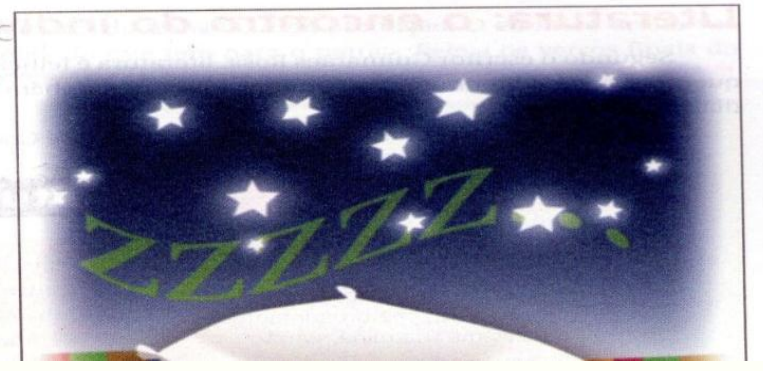

(Português: linguagens, 2005)

\section{A questão 1}


O texto I foi publicado e trata do medo de algumas pessoas de dormir fora de casa. De acordo com o texto:

a) Esse medo se restringe às crianças?

b) Por que dormir fora de casa causa tanto desconforto às crianças?

menciona o jornal, suporte onde o discurso foi publicado, mas não aprofunda nas questões a) e b) a relação constitutiva e determinante que o discurso produzido entretém com o jornal. É importante ressaltar que os autores apenas mencionam o suporte que permite a circulação do discurso sem estabelecer uma relação estreita e restritiva entre esse suporte, a organização e os efeitos de sentido produzidos por esse discurso. Desse modo, o suporte, nessa questão, figura apenas como uma informação que não é aproveitada nas questões que se seguem ao enunciado-base.

É interessante notar que o jornal onde foi publicado o artigo de opinião é um jornal de circulação nacional, cujos artigos, notícias e entrevistas são considerados de boa qualidade, veiculadores da verdade e, por isso, dignos da confiança dos leitores brasileiros. Assim, a legitimação dos sentidos produzidos pelo discurso não se dá apenas pela autoridade que a autora possui em questões sobre crianças e pré-adolescentes ou pelos discursos dos especialistas que são citados, mas também pelo meio que o faz circular socialmente, qual seja, o jornal Folha de São Paulo. O fato de ter sido publicado num jornal de tiragem nacional agrega a esse discurso um efeito de transparência que, por um lado, o legitima e, por outro, o apresenta como uma verdade a ser aceita e reproduzida.

Além do próprio jornal, suporte veiculador do discurso, outros aspectos, vinculados a esse suporte, poderiam ser levados em consideração a fim de pensar o modo de enunciação do texto analisado, tais como a data de publicação, o momento histórico da publicação, a seção onde o artigo foi publicado, as seções que o antecedem e as que vêm depois, as imagens que $o$ acompanham, bem como outros textos relacionados e que, de alguma forma, respondem a esse discurso. O estatuto do jornal e o estatuto dos objetos linguísticos e imagéticos que povoam as margens do texto mantêm com ele 
uma relação determinante, de modo que "é inegável que as mediações materiais não vêm acrescentar-se ao texto como circunstâncias contingentes, mas em vez disso intervêm na própria constituição de sua 'mensagem'" (MAINGUENEAU, 2006:213).

No enunciado-base da questão 2, O texto II foi criado pelo escritor Moacyr Scliar a partir da reportagem lida sobre o medo.

a) Qual dos dois textos trata de um problema concreto da realidade?

b) E qual deles cria uma história ficcional a partir de dados da realidade?,

não encontramos nenhuma referência ao suporte material onde a crônica Tormento não tem idade do escritor Moacyr Scliar foi veiculada. Esse apagamento do suporte na análise do Texto II impossibilita uma reflexão acerca dos efeitos do meio material na organização do discurso e dos mecanismos de legitimação desse mesmo discurso que, por sua vez, passam também pelos lugares sociais de circulação e pelo estatuto dos meios materiais de transmissão.

Num primeiro momento, nossos dados apontaram para uma lacuna bastante significativa existente entre a teoria adotada pelos autores e 0 encaminhamento dado às atividades de leitura. Embora afirmem que o ensino de leitura e compreensão esteja embasado nos pressupostos teóricos da Análise do Discurso, encontramos atividades que exigem do aluno-leitor o reconhecimento de aspectos formais do texto a fim de justificar o seu pertencimento a determinado movimento literário. Durante a análise, percebeuse também que aspectos discursivos figuram no enunciado das questões com o objetivo de levar o aluno-leitor a inferir determinados sentidos e, raras vezes, para fazê-lo refletir sobre o funcionamento discursivo do texto. Em todas as questões analisadas, percebemos uma forte tendência por parte dos autores em reiterar uma prática de leitura aos moldes da perspectiva tradicional, embora expressem assumir uma perspectiva sociointeracionista e afirmem buscar na Análise do Discurso contribuições teóricas para o trabalho com 0 ensino de língua materna, escrita e leitura. 


\section{Referências bibliográficas}

BAKHTIN, M. Estética da criação verbal. 4. ed. São Paulo: Martins Fontes, 2006.

BAKHTIN, M. M.; VOLOSHINOV, V. N. Discurso na Vida e Discurso na Arte (sobre a poética sociológica). Trad. De Carlos Alberto Faraco \& Cristóvão Tezza [para fins didáticos]. Versão da língua inglesa de I. R. Titunik a partir do original russo, 1976.

- Marxismo e filosofia da linguagem: problemas fundamentais do método sociológico na ciência da linguagem. 10. ed. São Paulo: Hucitec, 2002.

CEREJA, W. R.; MAGAlHÃES, T. C. Português: linguagens. v 1, 2 e 3.5 ed. São Paulo: Atual Editora, 2005.

MAINGUENEAU, D. O contexto da obra literária. São Paulo: Matins Fontes, 1995.

. Análise de textos de comunicação. 4. ed. São Paulo: Cortez, 2005.

. Discurso literário. São Paulo: Contexto, 2006.

. Cenas da Enunciação. POSSENTI, S.; SOUZA-E-SILVA, M. C. P. (org.) São Paulo: Parábola Editorial, 2008.

ORLANDI, E. A linguagem e seu funcionamento: as formas do discurso. 4. ed. Campinas: Pontes: 2001a.

. Discurso e texto: formulação e circulação dos sentidos. São Paulo: Pontes, 2001b.

SIGNORINI, I. Repensando a questão da língua legítima na sociedade democrática. In: MOITA LOPES, L. P. (Org.). Novos modos de teorizar e fazer Lingüística Aplicada, 2004.

SOUZA, D. M. Autoridade, Autoria e Livro didático. In: CORACINI, M. J. R. F. (Org.) Interpretação, Autoria e Legitimação do Livro didático. Campinas, SP: Pontes, 1999.

Artigo recebido em: 29 de abril de 2013

Artigo aprovado em: 9 de junho de 2013 
Sobre o autor:

Mestre em Linguística pela Universidade Federal de Alagoas - UFAL. 